\title{
Lack of Association between Interleukin-1 $\beta$ Gene Polymorphism (rs16944) and Chronic Periodontitis: From a Case-Control Studies to an Updated Meta-Analysis
}

\author{
Seoung-Jin Hong, ${ }^{1}$ Sang Wook Kang $\mathbb{D}^{2},{ }^{2}$ Su Kang Kim $\left(\mathbb{D},{ }^{3}\right.$ Young Sik Kim, ${ }^{4}$ \\ and Ju Yeon Ban $\mathbb{B D}^{2}$ \\ ${ }^{1}$ Department of Prosthodontics, Kyung Hee University Dental Hospital, Seoul, Republic of Korea \\ ${ }^{2}$ Department of Dental Pharmacology, College of Dentistry, Dankook University, Cheonan, Republic of Korea \\ ${ }^{3}$ Department of Biomedical Laboratory Science, Catholic Kwandong University, Gangneung, Republic of Korea \\ ${ }^{4}$ Management Research Institute, Kyung Hee University, Seoul, Republic of Korea \\ Correspondence should be addressed to Ju Yeon Ban; jyban@dankook.ac.kr
}

Received 18 August 2018; Accepted 31 October 2018; Published 11 December 2018

Academic Editor: Silvia Angeletti

\begin{abstract}
Copyright (C) 2018 Seoung-Jin Hong et al. This is an open access article distributed under the Creative Commons Attribution License, which permits unrestricted use, distribution, and reproduction in any medium, provided the original work is properly cited.
\end{abstract}

\begin{abstract}
Background. Interleukin-1 $\beta$ (IL-1 $\beta$ ) plays an important role as a mediator of various inflammatory responses in chronic periodontitis. Several studies have investigated the potential relationship between IL-1 $\beta$ polymorphism (rs16944) and susceptibility to chronic periodontitis; inflammatory process is involved, but conclusions is still controversial. Objective. The aim of this study was to determine whether the IL-1 $\beta$ polymorphism (rs16944) is associated with susceptibility to chronic periodontitis. Material and Methods. For the case-control study, 51 patients with chronic periodontitis and 33 healthy control patients were recruited in the study. Genotyping was conducted by direct sequencing. SNPStats and SPSS 18.0 were used for the analysis of genetic data and to evaluate odds ratios, $95 \%$ confidence intervals, and $P$ values; logistic regression models were used. And to perform meta-analysis, studies about IL-1 $\beta$ polymorphism (rs16944) and chronic periodontitis were searched in PubMed, Embase, Google Scholar, and Korean Studies Information Service System (KISS) electronic databases until July 2017. Results. In our case-control study, no significant relationship was revealed between IL-1 $\beta$ polymorphism (rs16944) and chronic periodontitis $(P>0.05$ in each model). When combined with the previous studies in the meta-analysis, the result was not associated with chronic periodontitis in any of the models (CC vs. CT + TT: OR $=0.97,95 \% \mathrm{CI}=0.762-1.246$; $\mathrm{CC}+\mathrm{CT}$ vs. TT: $\mathrm{OR}=0.90,95 \% \mathrm{CI}=0.658-1.232$; and $\mathrm{C}$ vs. $\mathrm{T}: \mathrm{OR}=0.93,95 \% \mathrm{CI}=0.774-1.128)$. The subgroup analysis stratified by ethnicity showed a weak association between the IL-1 $\beta$ polymorphism (rs16944) and chronic periodontitis in the Caucasian population (recessive model, $\mathrm{OR}=1.34,95 \% \mathrm{CI}=1.017-1.758, P=0.037$ ). Conclusion. Evidences from a case-control study and the metaanalysis suggest that IL-1 $\beta$ polymorphism (rs16944) is not associated with susceptibility to chronic periodontitis.
\end{abstract}

\section{Introduction}

Periodontitis, one of the most common infectious diseases, is the major cause of tooth extraction in the elderly population [1]. According to the Organisation for Economic Cooperation and Development (OECD), in 2014, the elderly accounted for $25.06 \%$ of the population in Japan, $21.45 \%$ in Germany, $21.25 \%$ in Italy, $19.94 \%$ in Finland, $18.31 \%$ in
Spain, and $12.66 \%$ in Korea and this number is continuously increasing [2]. With the increase of elderly population, the prevalence and social burden of periodontitis increase and demands on the efficient treatment of the disease also increase [3]. Thus, the importance of risk factor-based preventive strategies of periodontitis has been getting attention. Periodontitis is an inflammatory disease caused by several factors, including both genetic and environmental risk 
factors. Many researchers agree that the susceptibility to periodontal disease is at least partially influenced by a genetic factor [4].

The interleukin-1 beta (IL-1 $\beta$ ) gene located at $2 \mathrm{q} 14$ encodes the IL- $1 \beta$ protein which plays an important role as a mediator in a variety of inflammatory response as well as in bone metabolism $[5,6]$. A previous study showed that the amount of IL- $1 \beta$ mRNA expression is much higher in a group affected by chronic periodontitis than in the control group [7]. At the IL- $1 \beta$ transcription site, three polymorphisms at base pair positions $+3954 / 3953 \quad(\mathrm{C} \rightarrow \mathrm{T}$, rs1143634), $-511(\mathrm{C} \rightarrow \mathrm{T}, \mathrm{rs16944})$, and $-31 \quad(\mathrm{~T} \rightarrow \mathrm{C}$, rs1143627) caused transitions between $\mathrm{C}$ and $\mathrm{T}$ [8-10]. IL$1 \beta$ polymorphism (rs16944) is one of the most commonly investigated polymorphism regarding susceptibility to chronic periodontitis. Kornman et al. reported on the relationship between the IL- $1 \beta$ polymorphism (rs16944) and periodontal diseases in a population of European descent for the first time in 1997 [11]. Since then, many studies investigated the relationship between IL-1 $\beta$ polymorphism (rs16944) and chronic periodontitis, with many results that do not coincide and remain debatable. The discrepancy in results may be due to heterogeneity between studies, as well as small sample sizes. To overcome issues due to small sample sizes and error from inadequate statistical power, meta-analysis is performed. To obtain more reliable results on the relationship between the IL- $1 \beta$ polymorphism (rs16944) and the susceptibility to chronic periodontitis, we performed a case-control study and meta-analysis with all eligible studies.

The purpose of this study was to evaluate the association of IL-1 $\beta$ polymorphism (rs16944) and the susceptibility to chronic periodontitis from a new case-control study and then to further perform an updated meta-analysis to derive a more precise conclusion.

\section{Materials and Methods}

2.1. Participants for Case and Control in the Present Study. To investigate the relationship between IL-1 $\beta$ gene polymorphism (rs16944) and the susceptibility to chronic periodontitis, 51 patients with chronic periodontitis and 33 nonperiodontitis controls were recruited. The criteria for diagnosis for chronic periodontitis and control groups are described in Kang et al. [12]. This study was approved by the Institutional Review Board of College of Dentistry, Dankook University, Cheonan, Republic of Korea (IRB number: H-1204/004/001). Written consent forms were received from all subjects.

2.2. DNA Extraction and Genotyping. A previous study reported that oral epithelial cells near teeth in patients with gingivitis and periodontitis underwent changes such as proliferation, DNA damage, or apoptosis [13]. Collection of genomic DNA by buccal swabs is a simple and low-cost means and showed an adequate polymerase chain reaction results for genetic studies [14]. Thus, buccal swabs were collected to obtain genomic DNA from the patients [15]. Briefly, the patients were asked to wash their mouth with water, and we confirmed that no substance obstructed the DNA typing methods before collecting the cells from the inside of a patient's mouth, physically. For the buccal region of each cheek, two sterilized swabs were used to collect cells. A swab scraping was conducted over 10 times for collecting sufficient amount of epithelial cells from the side of the cheek. Each DNA sample was extracted according to the protocol of the DNA isolation reagent kit as previously described (Roche, Mannheim, Germany) [16].

\subsection{Statistical Analysis for Case and Control in the Present} Study. The Hardy-Weinberg equilibrium (HWE) was estimated using SNPStats (http://bioinfo.iconcologia.net/ SNPstats) in the control group. Genotype models (codominant, dominant, recessive, and log-additive models) were applied to determine relationship between differences in genotype frequencies between the chronic periodontitis group and the control group. Logistic regression was used for the analysis. SNPStats and SPSS 18.0 (SPSS Inc., Chicago, IL, USA) were used for the statistical analysis. Logistic regression was conducted to evaluate the odds ratio (OR), 95\% confidence intervals (CI), and $P$ value. For statistical tests, the level of significant $P$ value was set at 0.05 .

2.4. Meta-Analysis. To further investigate the association of IL-1 $\beta$ polymorphism (rs16944) with chronic periodontitis, a meta-analysis combining published literature and our current study was performed. Studies about IL- $1 \beta$ polymorphism (rs16944) and chronic periodontitis were searched in electronic databases including PubMed, Embase, Google of Scholar, and Korean Studies Information Service System (KISS) up to July 2017 using the keywords "Interleukin-1 $\beta$ ", "IL1B”, “rs16944", or "IL1B-511”, AND “polymorphism”, "polymorphisms", or "variant" AND “alveolar bone loss", "periodontitis", or "periodontal disease". First, we screened the titles and abstracts, and then examined the full text of screened articles. Some studies were included by manual search from references in related original studies or review articles.

Inclusion criteria were the following: (1) the study about the association between IL-1 $\beta$ polymorphism (rs16944) and chronic periodontitis, (2) a case-control study, and (3) sufficient genotype and allele distribution data of the IL- $1 \beta$ polymorphism (rs16944) in the control group and the chronic periodontitis group to calculate an odds ratio (OR) with a 95\% confidence interval (CI). The data of the first author's name, published year, country, ethnicity, sample size of the control and chronic periodontitis, and genotype frequencies of IL-1 $\beta$ polymorphism (rs16944) in the control and chronic periodontitis groups were extracted from the included studies.

Statistical analysis was performed by meta-analysis software (Comprehensive Meta-Analysis; Biostat Inc., NJ, USA). The random effects model or the fixed effects model was selected according to the degree of heterogeneity. The $I^{2}$ statistic for inconsistency and the $\chi^{2}$ distribution of Cochran $Q$ statistic were used to assess heterogeneity across studies. A $\chi^{2}$ test-based $Q$ statistic test and a $I^{2}$ test were performed to assess heterogeneity of the study. The $P$ value less 
TABLE 1: Analysis of genotypes of IL-1 $\beta$ polymorphism (rs16944) with chronic periodontitis.

\begin{tabular}{|c|c|c|c|c|c|}
\hline Model & Genotype & Control $N(\%)$ & Chronic periodontitis $N(\%)$ & OR (95\% CI) & $P$ \\
\hline \multirow{3}{*}{ Codominant } & $\mathrm{C} / \mathrm{C}$ & $12(37.5 \%)$ & $11(22.0 \%)$ & 1 & \multirow{3}{*}{0.06} \\
\hline & $\mathrm{C} / \mathrm{T}$ & $12(37.5 \%)$ & $32(64.0 \%)$ & $2.91(1.01-8.34)$ & \\
\hline & $\mathrm{T} / \mathrm{T}$ & $8(25.0 \%)$ & $7(14.0 \%)$ & $0.95(0.26-3.51)$ & \\
\hline \multirow{2}{*}{ Dominant } & $\mathrm{C} / \mathrm{C}$ & $12(37.5 \%)$ & $11(22.0 \%)$ & 1 & \multirow{2}{*}{0.13} \\
\hline & $\mathrm{C} / \mathrm{T}-\mathrm{T} / \mathrm{T}$ & $20(62.5 \%)$ & $39(78.0 \%)$ & $2.13(0.80-5.67)$ & \\
\hline \multirow{2}{*}{ Recessive } & $\mathrm{C} / \mathrm{C}-\mathrm{C} / \mathrm{T}$ & $24(75.0 \%)$ & $43(86.0 \%)$ & 1 & \multirow{2}{*}{0.21} \\
\hline & $\mathrm{T} / \mathrm{T}$ & $8(25.0 \%)$ & $7(14.0 \%)$ & $0.49(0.16-1.51)$ & \\
\hline Log-additive & - & - & - & $1.10(0.57-2.14)$ & 0.77 \\
\hline
\end{tabular}

OR: odds ratio; CI: confidence interval.

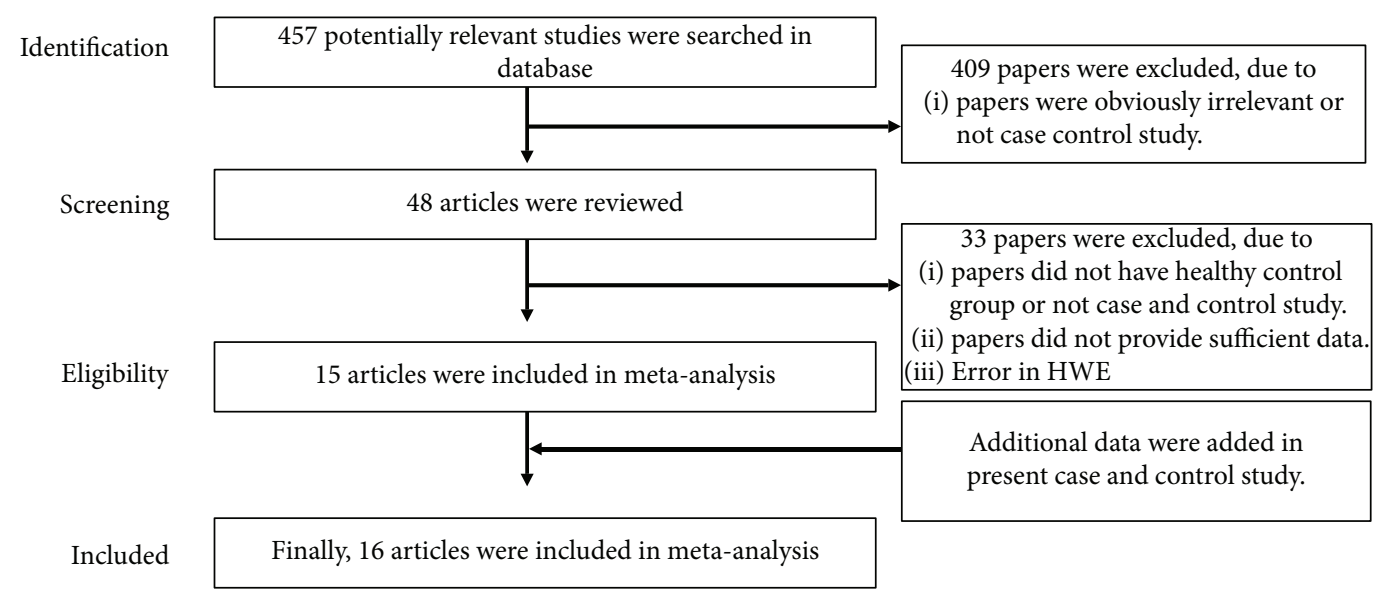

FIGURE 1: Flow chart illustrating the search strategy used for this meta-analysis to identify studies that evaluate the relationship between IL-1 $\beta$ polymorphism (rs16944) and susceptibility to chronic periodontitis.

than 0.05 of $Q$ was considered to be statistically significant. The fixed effects model was adopted if the result of the $Q$ test was $P>0.05$ or $I^{2}$ statistic was $<50 \%$, which indicated the statistically no significant heterogeneity in the metaanalysis. The random effects model was used when significant heterogeneity was detected among the included studies. Publication bias was evaluated by a funnel plot and Egger's test.

\section{Results and Discussion}

3.1. Case-Control Study. In the present study, association of the single nucleotide polymorphism of the IL- $1 \beta$ gene with susceptibility to chronic periodontitis was investigated. Table 1 shows analysis of genotype of IL- $1 \beta$ polymorphism (rs16944) with chronic periodontitis. In the control group, genotype distributions for IL-1 $\beta$ polymorphism (rs16944) were in $\mathrm{HWE}(P=0.178)$. Frequencies of $\mathrm{C} / \mathrm{C}, \mathrm{C} / \mathrm{T}$, and $\mathrm{T} /$ $\mathrm{T}$ genotypes were $37.5 \%, 37.5 \%$, and $25 \%$ in the control group, and $22 \%, 64 \%$, and $14 \%$ in the chronic periodontitis group, respectively (Table 1 ).

Any association between IL-1 $\beta$ polymorphism (rs16944) and chronic periodontitis was not observed. In the genotype analysis of the IL- $1 \beta$ polymorphism, all models (codominant, dominant, recessive, and log-additive models) showed no significant association with chronic periodontitis $(P>0.05)$.
3.2. Study Selection for Meta-Analysis. A total of 457 studies were screened using the mentioned search strategy. After deleting duplicates, a record screen was performed and 16 case-control studies were finally selected [17-31]. The search process and strategy of study selection are showed in Figure 1 . We reviewed 48 articles, and 30 articles were omitted because they did not have a healthy control group or not a case-control study or did not provide sufficient data. Among them, 3 studies were excluded because of inconsistency with HWE.

3.3. Characteristics of Eligible Studies. The characteristics of selected studies in meta-analysis, including our case-control study, are showed in Table 2 [31]. A total of 16 studies were included in the present meta-analysis. All studies were casecontrol studies. The 16 articles included 1540 patients with chronic periodontitis and 2472 healthy control subjects. Of the 16 included studies, 9 studies were conducted in Asian population and 7 studies were conducted in Caucasian population. All the studies conformed to HWE $(P>0.05)$.

3.4. Quantitative Synthesis. We evaluated the association between susceptibility to chronic periodontitis and IL- $1 \beta$ polymorphism (rs16944) (Table 3 ). There was no association observed between chronic periodontitis and IL- $1 \beta$ polymorphism (rs16944) in the allele, dominant, and recessive 
TABLE 2: Information of eligible studies included in the meta-analysis.

\begin{tabular}{|c|c|c|c|c|c|c|c|c|c|c|c|}
\hline \multirow{2}{*}{ First author } & \multirow{2}{*}{ Disease } & \multirow[t]{2}{*}{ Year } & \multirow{2}{*}{ Country } & \multirow[t]{2}{*}{ Ethnicity } & \multicolumn{3}{|c|}{$\begin{array}{c}\text { Chronic } \\
\text { periodontitis }\end{array}$} & \multicolumn{3}{|c|}{ Control } & \multirow{2}{*}{$\begin{array}{l}\text { HWE in the } \\
\text { control }\end{array}$} \\
\hline & & & & & $\mathrm{CC}$ & $\mathrm{CT}$ & $\mathrm{TT}$ & $\mathrm{CC}$ & $\mathrm{CT}$ & $\mathrm{TT}$ & \\
\hline Amirisetty et al. & \multirow{16}{*}{$\begin{array}{c}\text { Chronic } \\
\text { periodontitis }\end{array}$} & 2014 & India & Asian & 9 & 6 & 14 & 6 & 17 & 8 & 0.57 \\
\hline $\begin{array}{l}\text { Atanasovska-Stojanovska } \\
\text { et al. }\end{array}$ & & 2013 & Macedonia & Caucasian & 42 & 60 & 12 & 143 & 118 & 40 & 0.05 \\
\hline Braosi et al. & & 2012 & Brazil & Caucasian & 24 & 28 & 12 & 16 & 29 & 13 & 0.98 \\
\hline Brett et al. & & 2005 & $\begin{array}{l}\text { United } \\
\text { Kingdom }\end{array}$ & Caucasian & 27 & 26 & 4 & 51 & 39 & 10 & 0.53 \\
\hline Fan & & 2009 & China & Asian & 41 & 78 & 58 & 36 & 67 & 36 & 0.67 \\
\hline Gore et al. & & 1998 & United States & Caucasian & 13 & 15 & 4 & 13 & 16 & 3 & 0.54 \\
\hline Huang and Zhang & & 2004 & China & Asian & 25 & 58 & 99 & 21 & 49 & 19 & 0.33 \\
\hline Karasneh et al. & & 2011 & Jordan & Caucasian & 19 & 44 & 37 & 11 & 40 & 29 & 0.63 \\
\hline Lopez et al. & & 2009 & Chile & Caucasian & 58 & 117 & 49 & 29 & 107 & 72 & 0.28 \\
\hline Shete et al. & & 2010 & India & Asian & 7 & 48 & 45 & 9 & 43 & 48 & 0.89 \\
\hline Soga et al. & & 2003 & Japan & Asian & 21 & 33 & 10 & 14 & 34 & 16 & 0.61 \\
\hline Tanaka et al. & & 2014 & Japan & Asian & 45 & 54 & 32 & 284 & 518 & 217 & 0.50 \\
\hline Trevilatto et al. & & 2011 & Brazil & Brazilian & 22 & 35 & 12 & 17 & 23 & 4 & 0.33 \\
\hline Yang & & 2008 & China & Asian & 11 & 20 & 13 & 18 & 21 & 10 & 0.40 \\
\hline Zhang & & 2009 & China & Asian & 24 & 54 & 25 & 38 & 61 & 27 & 0.78 \\
\hline Present study & & 2017 & Korean & Asian & 11 & 32 & 7 & 12 & 12 & 8 & 0.18 \\
\hline
\end{tabular}

HWE: Hardy-Weinberg equilibrium.

TABLE 3: Overall analysis of the association between IL- $1 \beta$ polymorphism (rs16944) and susceptibility to chronic periodontitis.

\begin{tabular}{|c|c|c|c|c|c|c|c|c|}
\hline \multirow{2}{*}{ Models } & \multirow{2}{*}{ Group } & \multicolumn{2}{|c|}{ Heterogeneity } & \multirow{2}{*}{ Model } & \multirow{2}{*}{ OR } & \multirow{2}{*}{$95 \% \mathrm{CI}$} & \multirow{2}{*}{$P$} & \multirow{2}{*}{ Egger's $P$} \\
\hline & & $P$ & $I^{2}$ & & & & & \\
\hline \multirow{3}{*}{ C vs. T } & All & $<0.001$ & 63.39 & Random & 0.93 & $0.774-1.128$ & 0.48 & 0.45 \\
\hline & Asian & 0.001 & 68.53 & Random & 0.84 & $0.655-1.083$ & 0.18 & 0.85 \\
\hline & Caucasian & 0.028 & 57.71 & Random & 1.08 & $0.835-1.388$ & 0.57 & 0.27 \\
\hline \multirow{3}{*}{ CC vs. CT + TT } & All & 0.008 & 51.83 & Random & 0.97 & $0.762-1.246$ & 0.84 & 0.62 \\
\hline & Asian & 0.066 & 45.47 & Fixed & 0.93 & $0.750-1.158$ & 0.52 & 0.42 \\
\hline & Caucasian & 0.016 & 61.52 & Random & 1.11 & $0.738-1.665$ & 0.62 & 0.83 \\
\hline \multirow{3}{*}{$\mathrm{CC}+\mathrm{CT}$ vs. TT } & All & $<0.001$ & 67.01 & Random & 0.90 & $0.658-1.232$ & 0.51 & 0.76 \\
\hline & Asian & 0.001 & 70.45 & Random & 0.76 & $0.503-1.149$ & 0.19 & 0.77 \\
\hline & Caucasian & 0.313 & 15.32 & Fixed & 1.34 & $1.017-1.758$ & 0.037 & 0.83 \\
\hline
\end{tabular}

OR: odds ratio; CI: confidence interval. Bold numbers indicate a significant $P$ value.

models $(\mathrm{OR}=0.93,95 \% \mathrm{CI}=0.774-1.128, P=0.48$ in the allele model; $\mathrm{OR}=0.97,95 \% \mathrm{CI}=0.762-1.246, P=0.84$ in the dominant model; and $\mathrm{OR}=0.90,95 \% \mathrm{CI}=0.658-1.232$, $P=0.51$ in the recessive model, Table 3 and Figure 2).

In the subgroup analysis of the Asian population, there was also no association observed between chronic periodontitis and IL- $1 \beta$ polymorphism (rs16944) in the allele, dominant, and recessive models $(\mathrm{OR}=0.84,95 \% \mathrm{CI}=0.655-$ 1.083, $P=0.18$ in the allele model; $\mathrm{OR}=0.93,95 \%$ $\mathrm{CI}=0.750-1.158, P=0.52$ in the dominant model; and $\mathrm{OR}=0.76,95 \% \mathrm{CI}=0.503-1.149, P=0.19$ in the recessive model, Table 3 and Figure 3 ).

IL-1 $\beta$ polymorphism (rs16944) showed a weak association with chronic periodontitis in the Caucasian population
$(\mathrm{OR}=1.34,95 \% \mathrm{CI}=1.017-1.758, P=0.037$ in the recessive model). However, association between IL- $1 \beta$ polymorphism (rs16944) and chronic periodontitis was not observed in the allele $(\mathrm{OR}=1.08,95 \% \mathrm{CI}=0.835-1.388, P=0.27)$ and dominant $(\mathrm{OR}=1.11,95 \% \mathrm{CI}=0.738-1.665, P=0.83)$ models (Table 3 and Figure 4). Consequently, it is difficult to define significant association between IL-1 $\beta$ polymorphism (rs16944) and chronic periodontitis.

Table 3 and Figure 5 show the analysis of funnel plots for publication bias. Funnel plots were graphed by standard error plotted against the OR for each study. No evidence of asymmetry was indicated in the funnel plots $(P>0.05)$, and Egger's linear regression test showed that there was no publication bias $(P>0.05)$. 


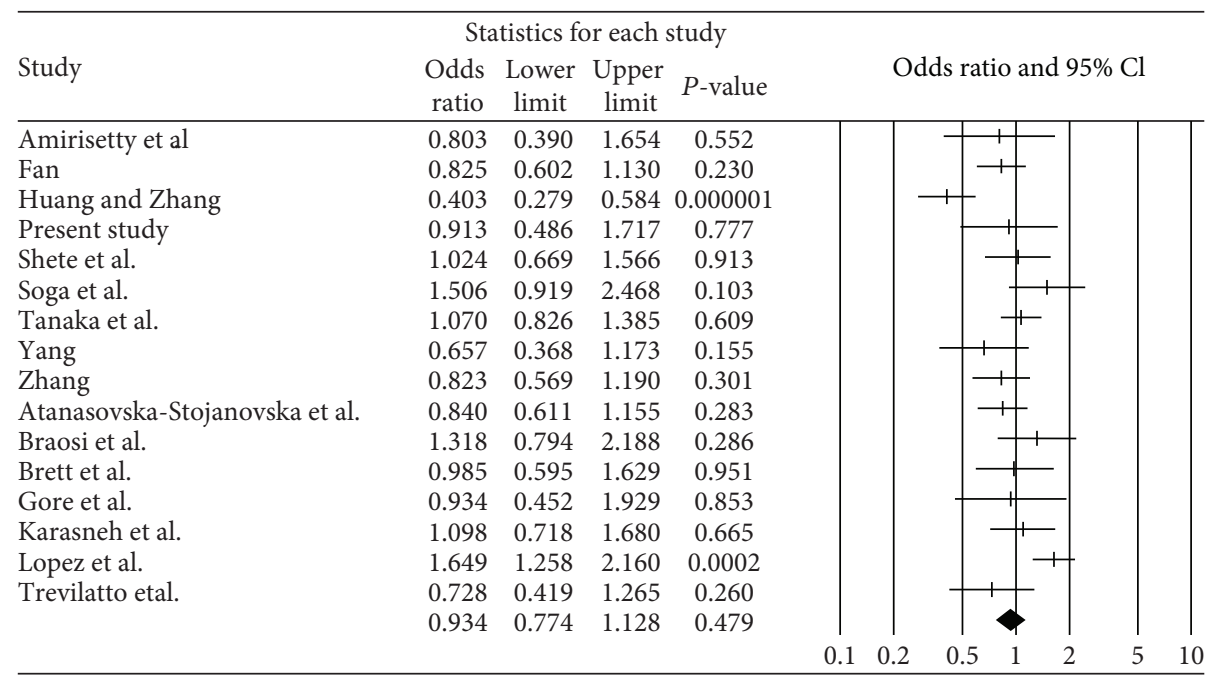

(a)

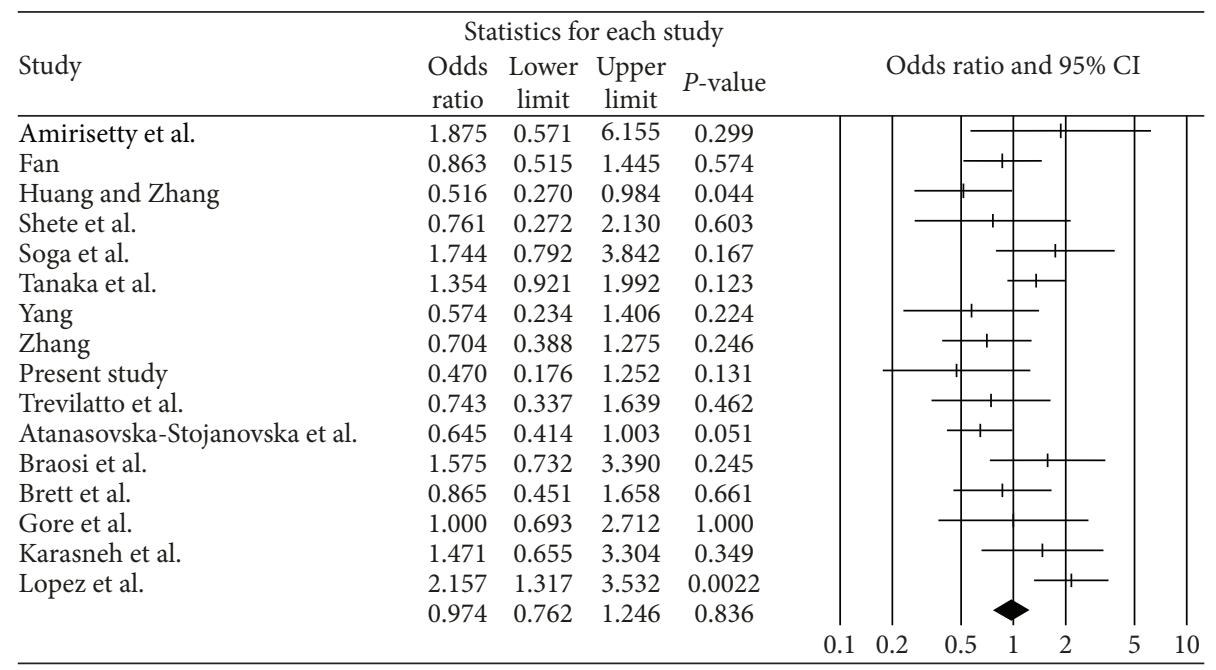

(b)

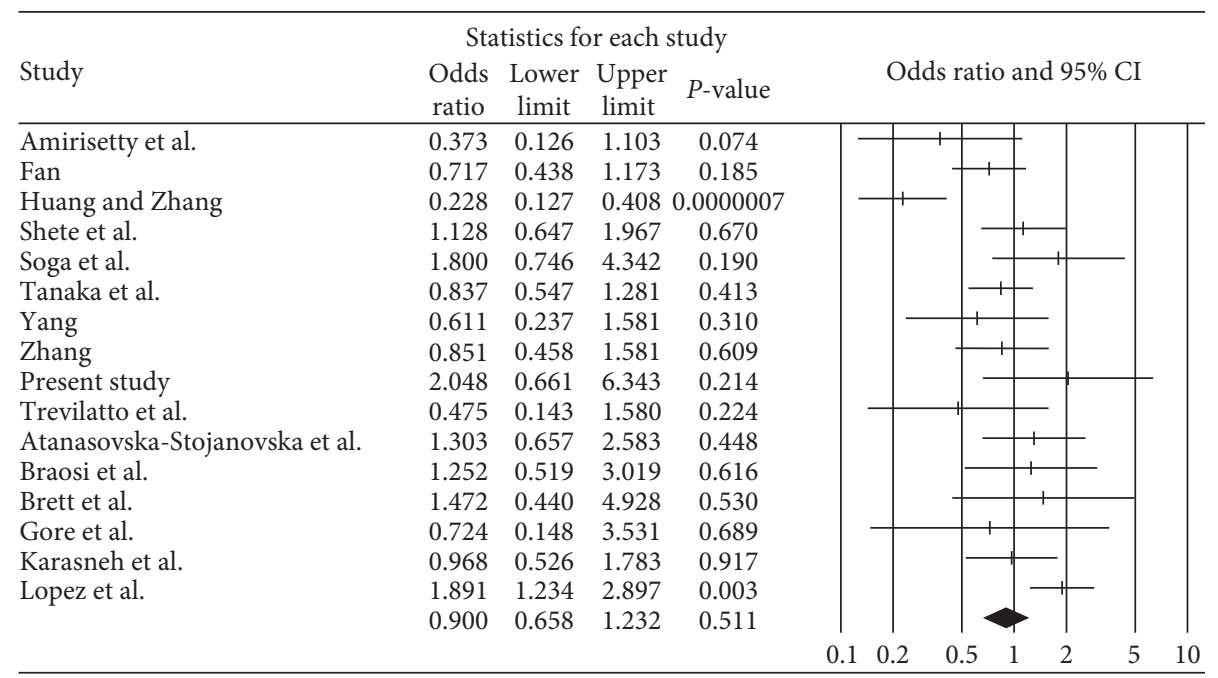

(c)

FIgure 2: Odds ratio and 95\% CI of individual and pooled data for the IL-1 $\beta$ polymorphism (rs16944) and susceptibility to chronic periodontitis. (a) $\mathrm{C}$ allele vs. $\mathrm{T}$ allele. (b) $\mathrm{C} / \mathrm{C}$ genotype vs. $\mathrm{C} / \mathrm{T}$ genotype $+\mathrm{T} / \mathrm{T}$ genotype. (c) $\mathrm{C} / \mathrm{C}$ genotype $+\mathrm{C} / \mathrm{T}$ genotype vs. $\mathrm{T} / \mathrm{T}$ genotype 


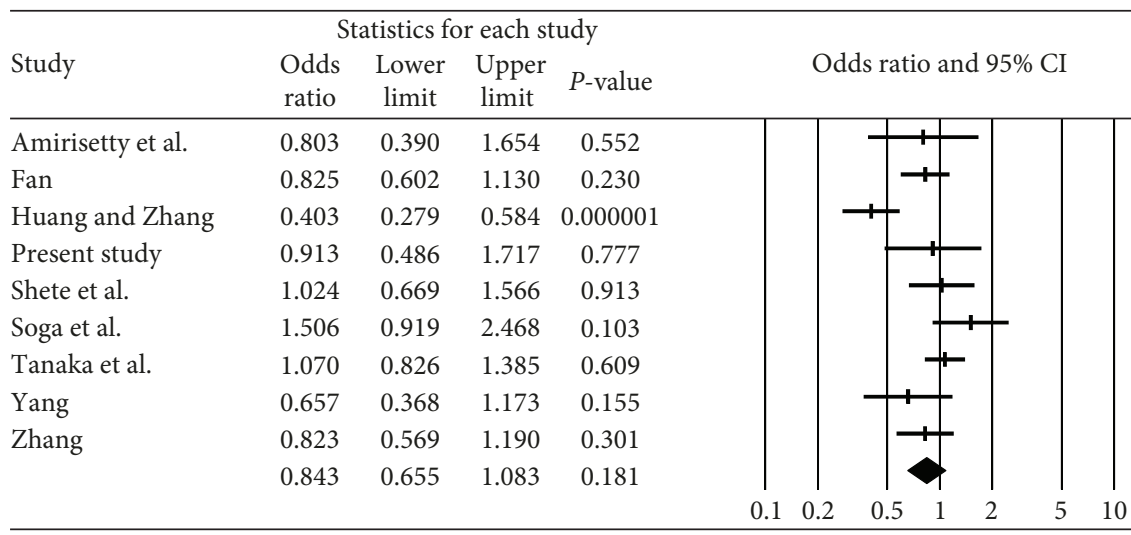

(a)

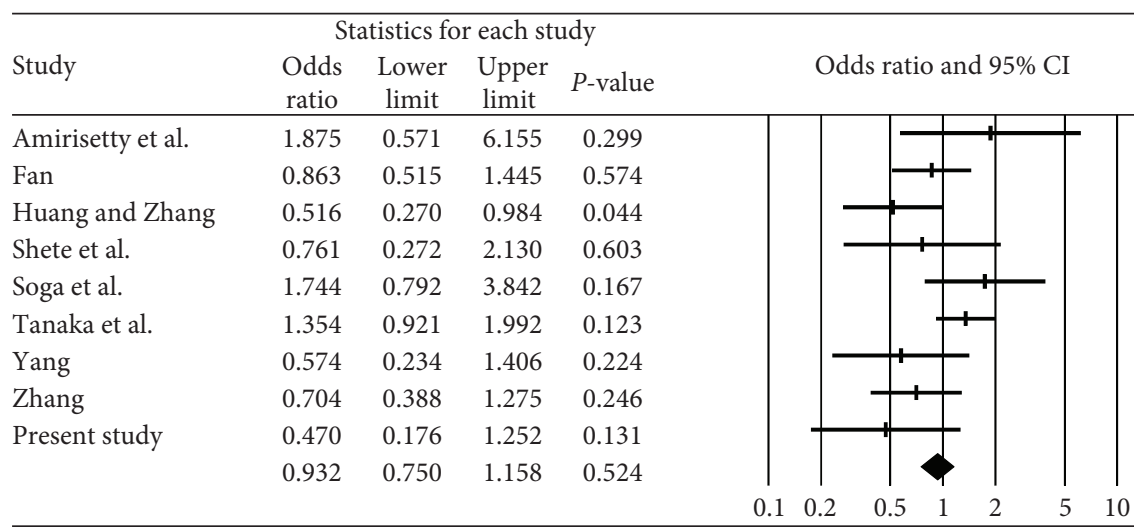

(b)

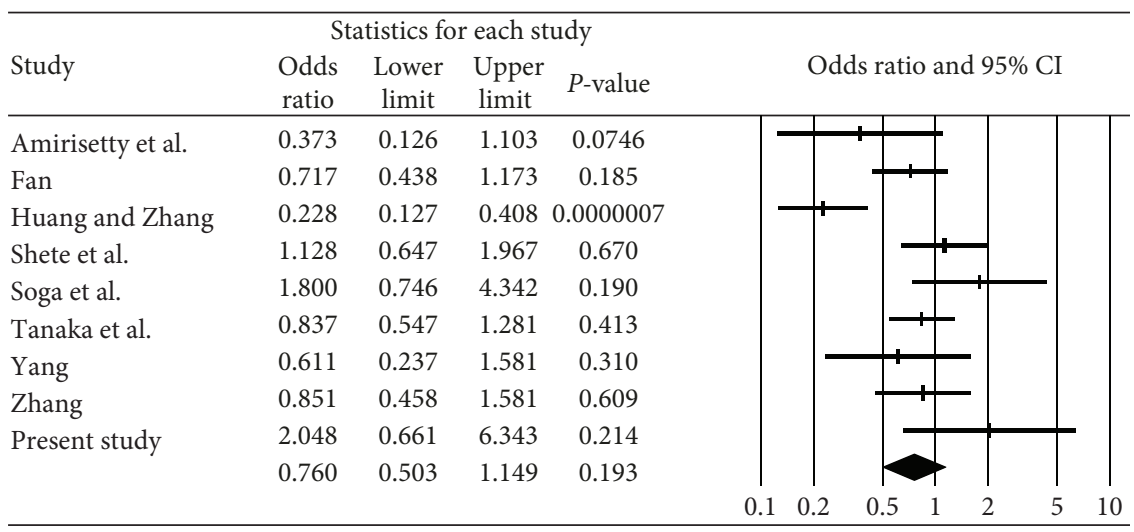

(c)

Figure 3: Odds ratio and 95\% CI of individual and pooled data for the IL-1 $\beta$ polymorphism (rs16944) and susceptibility to chronic periodontitis in Asian population. (a) $\mathrm{C}$ allele vs. $\mathrm{T}$ allele. (b) $\mathrm{C} / \mathrm{C}$ genotype vs. $\mathrm{C} / \mathrm{T}$ genotype $+\mathrm{T} / \mathrm{T}$ genotype (c) $\mathrm{C} / \mathrm{C}$ genotype $+\mathrm{C} / \mathrm{T}$ genotype vs. T/T genotype.

3.5. Discussion. It is not too much to emphasize the importance of existence of teeth in one's life. The presence of teeth is closely connected with one's daily activities and quality of life (QoL) [32]. Tooth loss is a critical factor in the impairment of QoL, and location and distribution of missing tooth plays a major role in the severity of the impairment [33]. Therefore, the preservation of natural teeth is very important. It contributes to a positive body image and increase in self-worth and positively influences QoL [34]. Likewise, proper dental prostheses or implants could compensate for tooth loss to improve QoL [35]. To this end, both social and individual healthcare budgets in the world are increasing continuously. According to the Korean National Health Insurance Service (NHIS), periodontitis is one of the most common oral diseases in Korea and the cost of health insurance exhibits a growing trend with NHIS expenditure [36]. Thus, the need for efficient prediction and risk factor-based periodontitis preventive strategies is rapidly growing both in clinical and economical terms. 


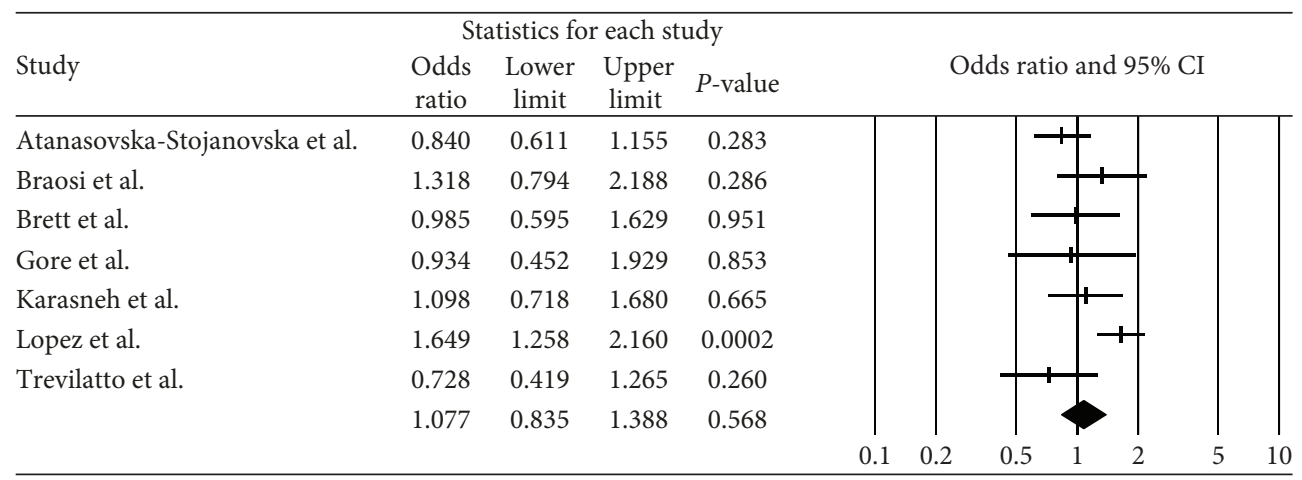

(a)

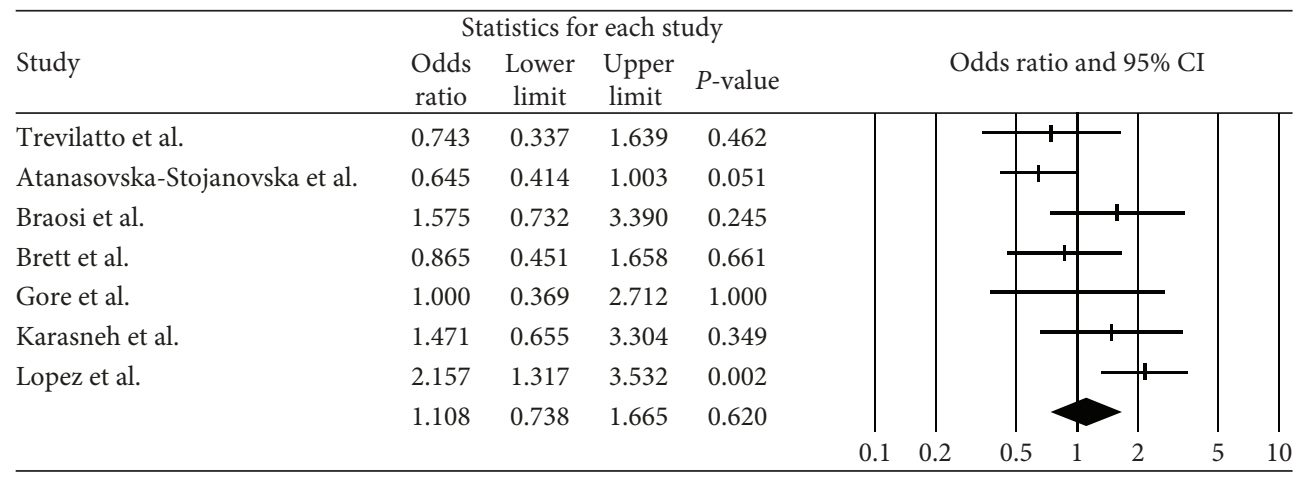

(b)

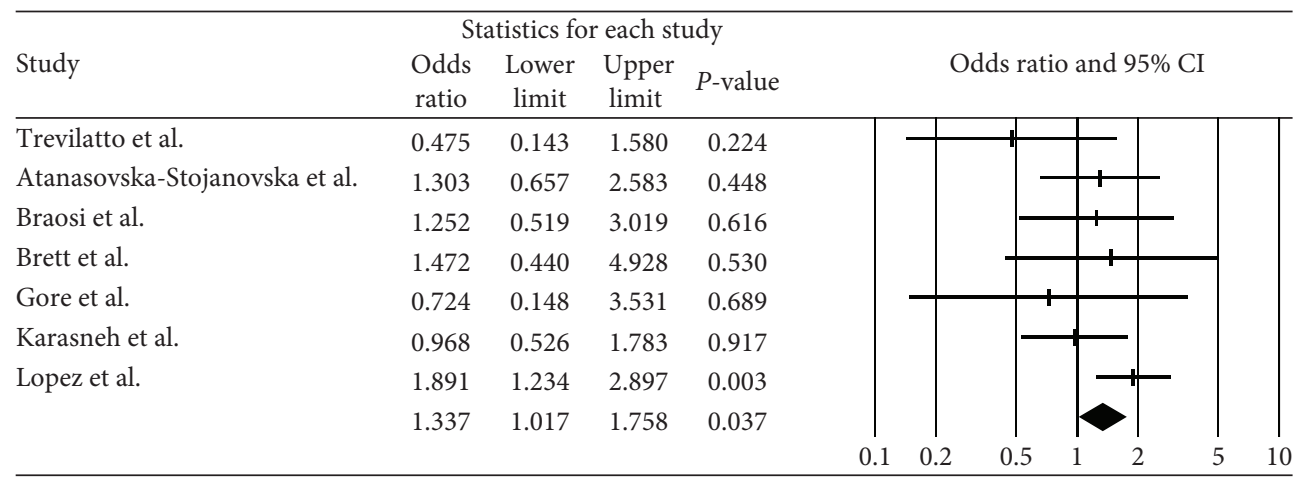

(c)

FIgURE 4: Odds ratio and 95\% CI of individual and pooled data for the IL-1 $\beta$ polymorphism (rs16944) and susceptibility to chronic periodontitis in Caucasian population. (a) $\mathrm{C}$ allele vs. $\mathrm{T}$ allele. (b) $\mathrm{C} / \mathrm{C}$ genotype vs. $\mathrm{C} / \mathrm{T}$ genotype $+\mathrm{T} / \mathrm{T}$ genotype. (c) $\mathrm{C} / \mathrm{C}$ genotype $+\mathrm{C} / \mathrm{T}$ genotype vs. T/T genotype.

IL- $1 \beta$ is expressed most abundantly in blood mononuclear cells and mediates host response [37]. IL- $1 \beta$ plays an important role in inflammation, regulating inflammatory pain hypersensitivity by modulating COX2 expression [38]. CD4+ T helper cells, important for host defense and immunity, selectively express Th17, even in the absence of TGFbeta signaling. IL- $1 \beta$ can also participate in this process [39]. Because of the role of IL-1 $\beta$ in these inflammations, there have been many studies on inflammatory diseases and polymorphisms of the IL- $1 \beta$ gene. IL- $1 \beta$ polymorphism may be associated with an increased risk of hypochlorhydria and gastric cancer by altering the level of IL- $1 \beta$ expression due to Helicobacter pylori infection [40]. Studies on inflammatory bowel disease in South Africa found more IL- $1 \beta$ gene mutations in the patient group than in the control group [41]. The IL-1 $\beta$ polymorphism (rs16944), one of the single nucleotide polymorphisms of IL- $1 \beta$, has been reported to be associated with various diseases, such as diabetic nephropathy in Korean type 2 diabetic patients [42], Parkinson's disease in Finnish patients [43], and Behçet's disease in Turkish patients [44].

Therefore, there have been many studies on periodontitis as one of the inflammatory diseases. Ever since the first reported study on the association between the IL- $1 \beta$ polymorphism (rs16944) and chronic periodontitis in a population of European descent [11], many studies have been undertaken to explore this association. However, results of individual studies have been inconclusive. There was a study 
C vs. T

Funnelplotof standard errorbylogoddsratio

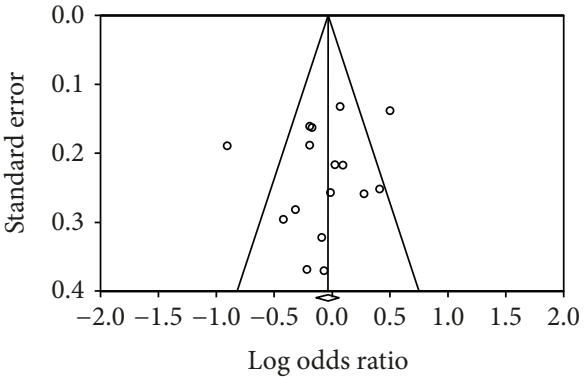

Funnelplotof standard errorbylogoddsratio

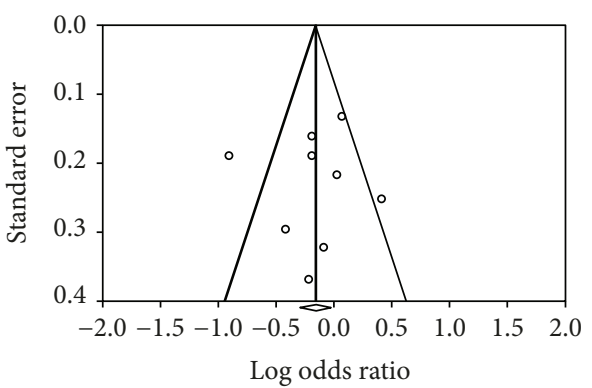

Funnelplotof standard errorbylogoddsratio

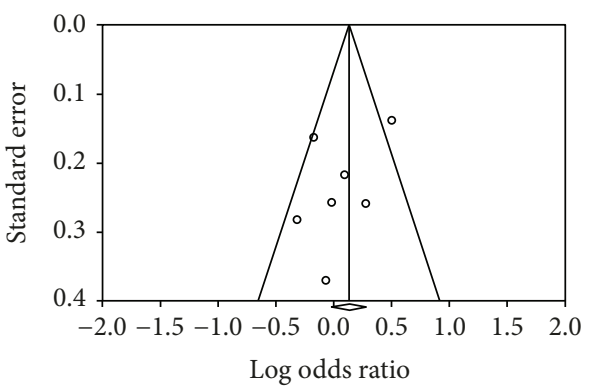

CC vs. CT + TT

Funnelplotof standard errorbylogoddsratio

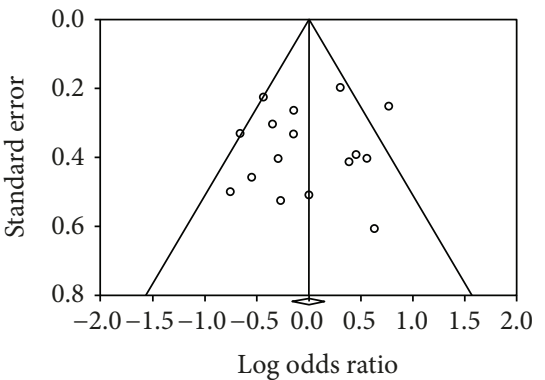

(a)

Funnelplotof standard errorbylogoddsratio

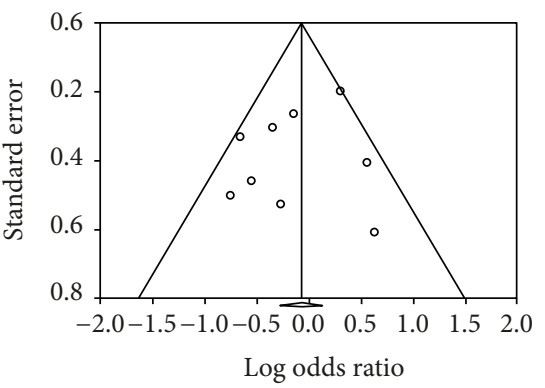

(b)

Funnelplotof standard errorbylogoddsratio

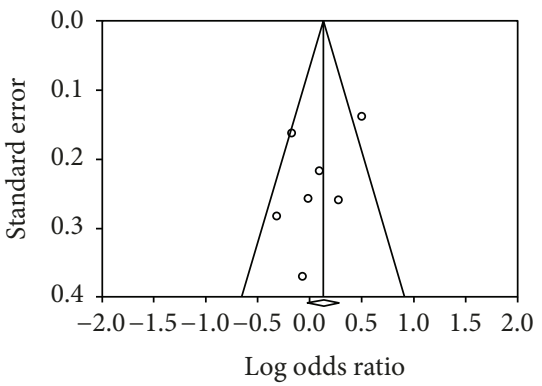

(c)
$\mathrm{CC}+\mathrm{CT}$ vs. TT

Funnelplotof standard errorbylogoddsratio

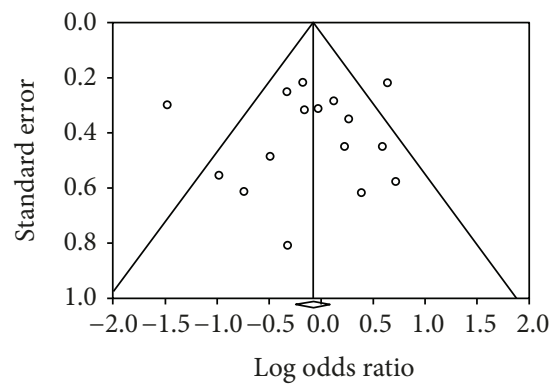

Funnelplotof standard errorbylogoddsratio

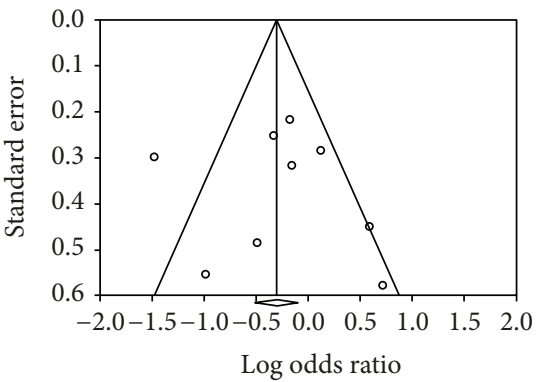

Funnelplotof standard errorbylogoddsratio

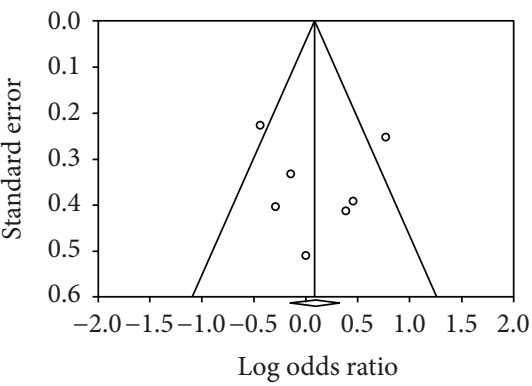

FIgURe 5: Funnel plot of publication bias for the IL-1 $\beta$ polymorphism (rs16944) and susceptibility to chronic periodontitis. (a) Funnel plot in all population. (b) Funnel plot in Asian population. (c) Funnel plot in Caucasian population.

suggested IL-1 $\beta$ polymorphism (rs16944) as a risk indicator for chronic periodontitis in Brazilians [28]. In contrast, another study in Japanese women showed an association between the genotype of IL-1 $\beta$ polymorphism (rs16944) and reduced risk of periodontitis [27]. A recent metaanalysis study in the Chinese population suggested association between IL-1 $\beta$ polymorphism (rs16944) variants and the risk of periodontitis [45].

In the present study, we have collected the previous studies conducted on the association between IL- $1 \beta$ polymorphism (rs16944) and chronic periodontitis. Our study included 1540 patients with chronic periodontitis and 2472 healthy control subjects in 16 articles. The result shows that the development of chronic periodontitis is not associated with IL-1 $\beta$ polymorphism (rs16944), except in the case of Caucasian population, where a weak statistical significance in the recessive model was detected $(P=0.037)$. Our present result for host response might partially explain this difference.

The purpose of our study was to find a significant relationship between IL-1 $\beta$ polymorphism (rs16944) and the chronic periodontitis, but our results failed to show the association. These findings should be interpreted with caution and have some limitations. We could not investigate various ethnic distributions because all studies included only Caucasian and Asian populations. Though environmental or habitual elements are key factors in the risk of chronic periodontitis and the pathophysiological processes are very complex, we cannot but consider only one genetic factor in this meta-analysis. With this regard, we have added a new original case-control study to the meta-analysis and have found some more accurate results by removing some papers 
outside of the HWE. The ethnic-specific genotypes CC, CT, and TT of rs16944 are known as $0.416,0.451$, and 0.133 in Caucasian, 0.279, 0.535, and 0.186 in Chinese, and 0.290, $0.465,0.244$ in the Japanese population, respectively. The genotype in our case-control study in the Korean population was $0.375,0.375$, and 0.250 . These differences among genotypes are likely to be the reason for the different results between ethnicities.

\section{Conclusion}

We evaluated the association between IL- $1 \beta$ polymorphism (rs16944) and chronic periodontitis in the present case and control study. We observed that IL- $1 \beta$ polymorphism (rs16944) was not associated with chronic periodontitis in the Korean population. We also evaluated the relationship between IL-1 $\beta$ polymorphism (rs16944) and chronic periodontitis using meta-analysis. A statistically meaningful association was detected with IL-1 $\beta$ polymorphism (rs16944) in the Caucasian population, but it is difficult to describe a strong association with chronic periodontitis due to insufficient statistical power. If more results in various populations would be accumulated in further studies, the relation between IL- $1 \beta$ polymorphism (rs16944) and chronic periodontitis would be clarified and that would help improving clinical prognosis.

\section{Data Availability}

Genotyping results of subjects participating in the casecontrol study are shown in Table 1. In addition, additional data used to support the findings of this study are available from the corresponding author upon request. The data supporting this meta-analysis are from previously reported studies and datasets, which have been cited within the text as references [15-29].

\section{Conflicts of Interest}

The authors declare no conflict of interests related to this study.

\section{Authors' Contributions}

Seoung-Jin Hong and Sang Wook Kang contributed equally to this work. Ju Yeon Ban conceived and planned the experiments and contributed to sample preparation. Su Kang Kim and Young Sik Kim performed the calculations and contributed to the interpretation of the results. Seoung-Jin Hong and Sang Wook Kang took the lead in writing the manuscript. All authors provided critical feedback and helped shape the research, analysis, and manuscript.

\section{Acknowledgments}

The present research was conducted by the research fund of Dankook University in 2015.

\section{References}

[1] R. C. Page and H. E. Schroeder, "Pathogenesis of inflammatory periodontal disease. A summary of current work," Laboratory Investigation; A Journal of Technical Methods and Pathology, vol. 34, no. 3, pp. 235-249, 1976.

[2] OECD, "Elderly population (indicator)," Journal, vol. 2016, 2016.

[3] S. H. Murdock and M. N. Hoque, "Current patterns and future trends in the population of the United States: implications for dentistry and the dental profession in the twenty-first century," The Journal of the American College of Dentists, vol. 65, no. 4, pp. 29-35, 1998.

[4] G. J. Seymour, "Importance of the host response in the periodontium," Journal of Clinical Periodontology, vol. 18, no. 6, pp. 421-426, 1991.

[5] C. A. Dinarello, "Biologic basis for interleukin-1 in disease," Blood, vol. 87, no. 6, pp. 2095-2147, 1996.

[6] D. N. Tatakis, "Interleukin-1 and bone metabolism: a review," Journal of Periodontology, vol. 64, 5 Supplement, pp. 416-431, 1993.

[7] L. Yin, L. Li, Y. Pan, Y. Tan, and A. He, "IL-1 beta mRNA and TNF-alpha mRNA expression in gingival tissues of patients with adult periodontitis," Hua Xi Kou Qiang Yi Xue Za Zhi, vol. 19, no. 5, pp. 318-321, 2001.

[8] S. Bird, J. Zou, T. Wang, B. Munday, C. Cunningham, and C. J. Secombes, "Evolution of interleukin-1beta," Cytokine \& Growth Factor Reviews, vol. 13, no. 6, pp. 483-502, 2002.

[9] J. Xu, Z. Yin, S. Cao et al., "Systematic review and metaanalysis on the association between IL-1B polymorphisms and cancer risk," PLoS One, vol. 8, no. 5, article e63654, 2013.

[10] W. T. Yin, Y. P. Pan, and L. Lin, “Association between $I L-1 \alpha$ rs17561 and $I L-1 \beta$ rs1143634 polymorphisms and periodontitis: a meta-analysis," Genetics and Molecular Research, vol. 15, no. $1,2016$.

[11] K. S. Kornman, A. Crane, H. Y. Wang et al., "The interleukin-1 genotype as a severity factor in adult periodontal disease," Journal of Clinical Periodontology, vol. 24, no. 1, pp. 72-77, 1997.

[12] S. W. Kang, S. K. Kim, J. H. Chung, and J. Y. Ban, “Assessment of CASP gene polymorphisms in periodontal disease," Genetics and Molecular Research, vol. 14, no. 4, pp. 1806918077, 2015.

[13] F. Jarnbring, E. Somogyi, J. Dalton, A. Gustafsson, and B. Klinge, "Quantitative assessment of apoptotic and proliferative gingival keratinocytes in oral and sulcular epithelium in patients with gingivitis and periodontitis," Journal of Clinical Periodontology, vol. 29, no. 12, pp. 1065-1071, 2002.

[14] A. H. Walker, D. Najarian, D. L. White, J. F. Jaffe, P. A. Kanetsky, and T. R. Rebbeck, "Collection of genomic DNA by buccal swabs for polymerase chain reaction-based biomarker assays," Environmental Health Perspectives, vol. 107, no. 7, pp. 517-520, 1999.

[15] S. W. Kang, S. Y. Han, S. B. Lim, K. B. Cho, and J. Y. Ban, “ACE insertion/deletion polymorphism is associated with periodontal disease in Korean population," Archives of Oral Biology, vol. 60, no. 3, pp. 496-500, 2015.

[16] S. A. Yang, "Lack of association between glutathione stransferase mu 1 (GSTM1) gene polymorphisms and obesity," Journal of Exercise Rehabilitation, vol. 13, no. 5, pp. 608-612, 2017. 
[17] R. Amirisetty, R. P. Patel, S. Das, J. Saraf, A. Jyothy, and A. Munshi, "Interleukin $1 \beta(+3954,-511$ and -31$)$ polymorphism in chronic periodontitis patients from North India," Acta Odontologica Scandinavica, vol. 73, no. 5, pp. 343-347, 2015.

[18] A. Atanasovska-Stojanovska, M. Popovska, D. Trajkov, and M. Spiroski, "IL1 cluster gene polymorphisms in Macedonian patients with chronic periodontitis," Bratislavské Lekárske Listy, vol. 114, no. 7, pp. 380-385, 2013.

[19] A. P. R. Braosi, C. M. de Souza, S. M. Luczyszyn et al., "Analysis of IL1 gene polymorphisms and transcript levels in periodontal and chronic kidney disease," Cytokine, vol. 60, no. 1, pp. 76-82, 2012.

[20] J. A. Karasneh, K. T. Ababneh, A. H. Taha, M. S. Al-Abbadi, and W. E. Ollier, "Investigation of the interleukin-1 gene cluster polymorphisms in Jordanian patients with chronic and aggressive periodontitis," Archives of Oral Biology, vol. 56, no. 3, pp. 269-276, 2011.

[21] A. R. Shete, R. Joseph, N. N. Vijayan, L. Srinivas, and M. Banerjee, "Association of single nucleotide gene polymorphism at interleukin-1beta $+3954,-511$, and -31 in chronic periodontitis and aggressive periodontitis in Dravidian ethnicity," Journal of Periodontology, vol. 81, no. 1, pp. 62-69, 2010.

[22] N. J. Lopez, C. Y. Valenzuela, and L. Jara, "Interleukin-1 gene cluster polymorphisms associated with periodontal disease in type 2 diabetes," Journal of Periodontology, vol. 80, no. 10, pp. 1590-1598, 2009.

[23] P. M. Brett, P. Zygogianni, G. S. Griffiths et al., "Functional gene polymorphisms in aggressive and chronic periodontitis," Journal of Dental Research, vol. 84, no. 12, pp. 1149-1153, 2005.

[24] H. Y. Huang and J. C. Zhang, "Investigation on the association of interleukin-1 genotype polymorphism with chronic periodontitis," Hua Xi Kou Qiang Yi Xue Za Zhi, vol. 22, no. 5, pp. 415-419, 2004.

[25] R. M. Tamimi, S. E. Hankinson, D. Spiegelman, G. A. Colditz, and D. J. Hunter, "Manganese superoxide dismutase polymorphism, plasma antioxidants, cigarette smoking, and risk of breast cancer," Cancer Epidemiology and Prevention Biomarkers, vol. 13, no. 6, pp. 989-996, 2004.

[26] Y. Soga, F. Nishimura, H. Ohyama, H. Maeda, S. Takashiba, and Y. Murayama, "Tumor necrosis factor-alpha gene (TNFalpha) $-1031 /-863,-857$ single-nucleotide polymorphisms (SNPs) are associated with severe adult periodontitis in Japanese," Journal of Clinical Periodontology, vol. 30, no. 6, pp. 524-531, 2003.

[27] K. Tanaka, Y. Miyake, T. Hanioka, and M. Arakawa, "Relationship between IL1 gene polymorphisms and periodontal disease in Japanese women," DNA and Cell Biology, vol. 33, no. 4, pp. 227-233, 2014.

[28] P. C. Trevilatto, A. P. de Souza Pardo, R. M. Scarel-Caminaga et al., "Association of IL1 gene polymorphisms with chronic periodontitis in Brazilians," Archives of Oral Biology, vol. 56, no. 1, pp. 54-62, 2011.

[29] W. H. Fan, Investigation on Polymorphisms of Interleukin-6 and Interleukin-1 Genes as the Risk Factors for Coronary Heart Disease and Chronic Periodontitis, Southern Medical University, 2009.

[30] K. Yang, Interleukin-1 Genotype and the Association between Chronic Periodontitis and Coronary Heart Disease, Urumqi Xinjiang Medical University, 2008.
[31] L. Zhang, The Association of Interleukin-1 Gene Polymorphisms with the Susceptibility to Chronic Periodontitis in Dongxiang Populations from Northwestern China, Lanzhou University, 2009.

[32] Y. Yoshida, Y. Hatanaka, M. Imaki, Y. Ogawa, S. Miyatani, and S. Tanada, "Epidemiological study on improving the QOL and oral conditions of the aged-part 1: the relationship between the status of tooth preservation and QOL," Journal of Physiological Anthropology and Applied Human Science, vol. 20, no. 6, pp. 363-368, 2001.

[33] A. E. Gerritsen, P. F. Allen, D. J. Witter, E. M. Bronkhorst, and N. H. J. Creugers, "Tooth loss and oral health-related quality of life: a systematic review and meta-analysis," Health and Quality of Life Outcomes, vol. 8, no. 1, p. 126, 2010.

[34] D. Niesten, K. van Mourik, and W. van der Sanden, "The impact of having natural teeth on the QoL of frail dentulous older people. A qualitative study," BMC Public Health, vol. 12, no. 1, p. 839, 2012.

[35] M. Naito, H. Yuasa, Y. Nomura, T. Nakayama, N. Hamajima, and N. Hanada, "Oral health status and health-related quality of life: a systematic review," Journal of Oral Science, vol. 48, no. 1, pp. 1-7, 2006.

[36] Korean National Health Insurance Service, "Korean statistical annual report," Journal, vol. 2013, 2013.

[37] C. J. March, B. Mosley, A. Larsen et al., "Cloning, sequence and expression of two distinct human interleukin-1 complementary DNAs," Nature, vol. 315, no. 6021, pp. 641-647, 1985.

[38] T. A. Samad, K. A. Moore, A. Sapirstein et al., "Interleukin1beta-mediated induction of Cox-2 in the CNS contributes to inflammatory pain hypersensitivity," Nature, vol. 410, no. 6827 , pp. 471-475, 2001.

[39] K. Ghoreschi, A. Laurence, X. P. Yang et al., "Generation of pathogenic $\mathrm{T}_{\mathrm{H}} 17$ cells in the absence of TGF- $\beta$ signalling," Nature, vol. 467, no. 7318, pp. 967-971, 2010.

[40] E. M. El-Omar, M. Carrington, W.-H. Chow et al., "Interleukin-1 polymorphisms associated with increased risk of gastric cancer," Nature, vol. 404, no. 6776, pp. 398-402, 2000.

[41] O. Mwantembe, M. C. Gaillard, M. Barkhuizen et al., "Ethnic differences in allelic associations of the interleukin-1 gene cluster in South African patients with inflammatory bowel disease (IBD) and in control individuals," Immunogenetics, vol. 52, no. 3-4, pp. 249-254, 2001.

[42] S. H. Lee, C. G. Ihm, S. D. Sohn et al., "Polymorphisms in interleukin-1 beta and interleukin-1 receptor antagonist genes are associated with kidney failure in Korean patients with type 2 diabetes mellitus," American Journal of Nephrology, vol. 24, no. 4, pp. 410-414, 2004.

[43] K. M. Mattila, J. O. Rinne, T. Lehtimaki, M. Roytta, J. P. Ahonen, and M. Hurme, "Association of an interleukin 1B gene polymorphism (-511) with Parkinson's disease in Finnish patients," Journal of Medical Genetics, vol. 39, no. 6, pp. 400-402, 2002.

[44] A. A. Özçimen, K. Dilek, Ü. Bingöl et al., "IL-1 cluster gene polymorphisms in Turkish patients with Behçet's disease," International Journal of Immunogenetics, vol. 38, no. 4, pp. 295-301, 2011.

[45] H. F. Wang, F. Q. He, C. J. Xu et al., "Association between the interleukin-1 $\beta$ C-511T polymorphism and periodontitis: a meta-analysis in the Chinese population," Genetics and Molecular Research, vol. 16, no. 1, 2017. 


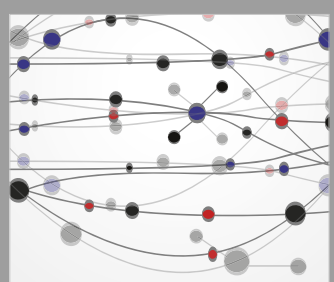

The Scientific World Journal
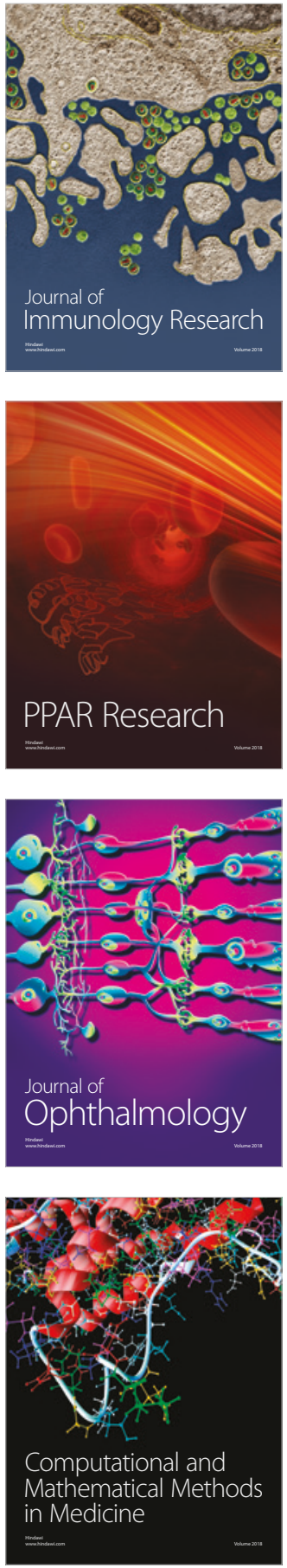

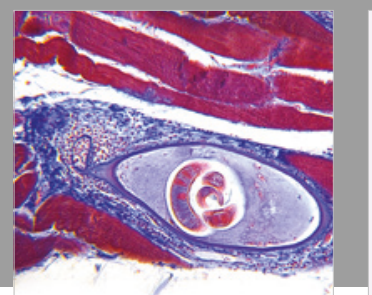

Gastroenterology Research and Practice

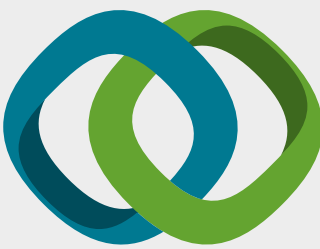

\section{Hindawi}

Submit your manuscripts at

www.hindawi.com
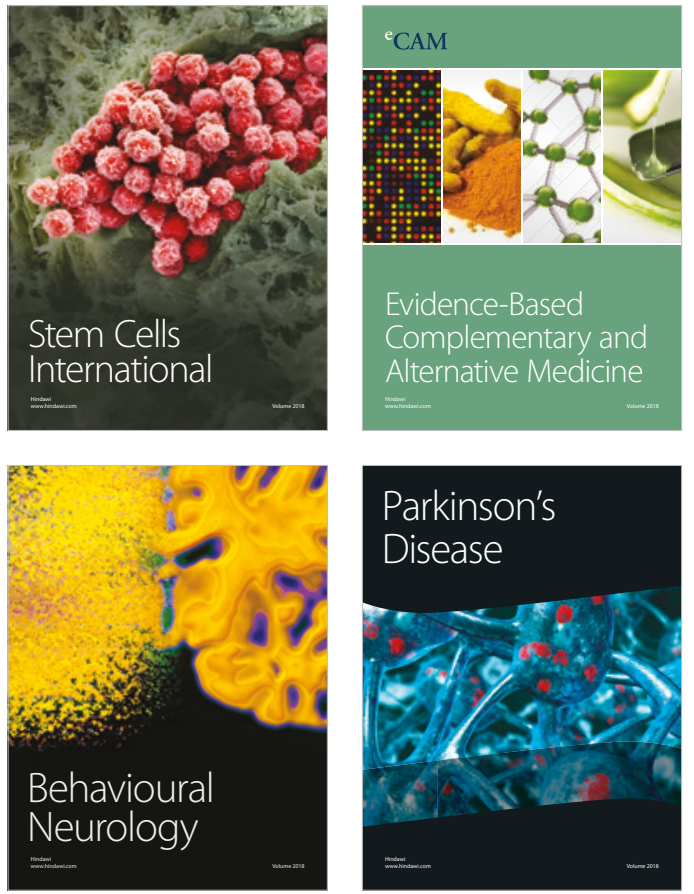

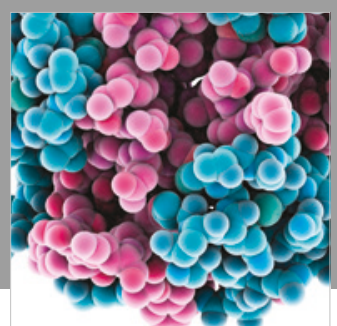

ournal of

Diabetes Research

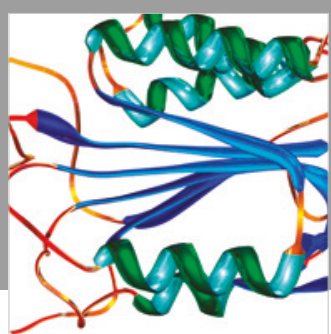

Disease Markers
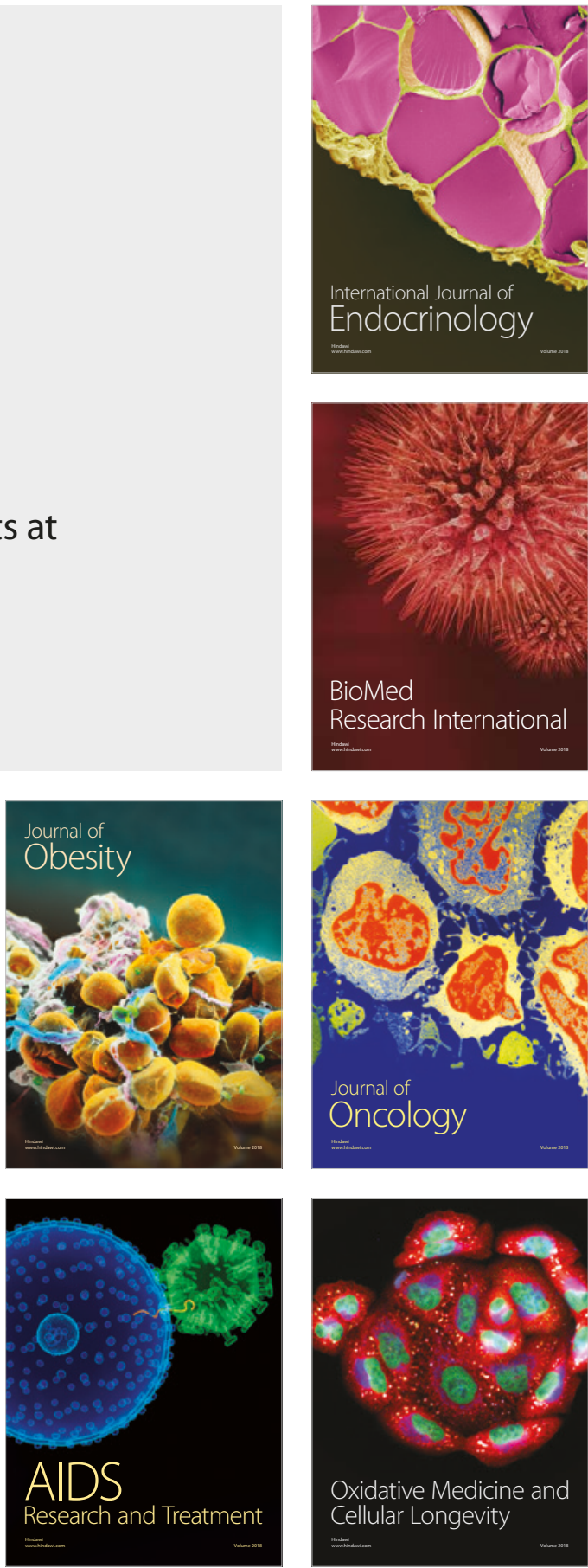